\title{
Lutzomyia naftalekatzi, a New Species of Phlebotomine Sand Fly (Diptera: Psychodidae) from Zona da Mata Region, Pernambuco, Brazil
}

\author{
Alda Lima Falcão/ ${ }^{+}$, José Dilermando Andrade Filho, \\ Francisco de Assis Almeida*, Sinval P Brandão Filho**
}

\begin{abstract}
Laboratório de Leishmanioses, Centro de Pesquisas René Rachou-Fiocruz, Av. Augusto de Lima 1715, 30190002 Belo Horizonte, MG, Brasil *Fundação Nacional de Saúde, Coordenação de Pernambuco, Recife, PE, Brasil

**Centro de Pesquisas Aggeu Magalhães-Fiocruz, Recife, PE, Brasil
\end{abstract}

Lutzomyia naftalekatzi, a new phlebotomine sand fly belonging to the L. aragaoi species group, is described from specimens collected in Zona da Mata region of Pernambuco, Brazil.

Key words: Lutzomyia naftalekatzi n. sp. - Phlebotominae - sand fly - Brazil

A new species was discovered among specimens of phlebotomine sand flies collected during studies on the eco-epidemiology and transmission of Leishmania in Zona da Mata, State of Pernambuco, Brazil (Felinto de Brito et al. 1993, Brandão-Filho et al. 1994). This species belongs to the Lutzomyia aragaoi (Costa Lima) species group and is named for Dr Naftale Katz of the Centro de Pesquisas René Rachou, Belo Horizonte, in recognition of his long and significant contribution to tropical medicine in Brazil. The description is based on characters proposed by the CIPA group (1990). All measurements are given in mm. Figures in parentheses refer to means of all specimens measured.

\section{DESCRIPTION}

\section{Lutzomyia naftalekatzi $\mathrm{n}$. sp.}

(Figs 1-26)

Holotype (male): very large sand fly, total length 4.47 (4.254 $\pm 0.218 \mathrm{~mm} ; \mathrm{n}=13)$. Head and thorax dark brown, pleurae paler than pronotum.

Head: length $0.290(0.303 \pm 0.009 ; n=13)$, not including relatively short clypeus of length $0.113(0.114 \pm 0.006 ; \mathrm{n}=13)$. Ratio head/clypeus 2.57:1. Interocular distance $0.150(0.149 \pm 0.003$; $\mathrm{n}=13$ ). Labrum also relatively short, length 0.200 $(0.196 \pm 0.011 ; \mathrm{n}=13)$. Lengths of palpomeres: 1 $-0.043(0.044 \pm 0.003 ; \mathrm{n}=13) ; 2-0.090(0.093 \pm$

This work was supported by CNPq, Fiocruz and FNS. ${ }^{+}$Corresponding author. Fax:+55-31-295.3566. E-mail: alda@cpqrr.fiocruz.br

Received 27 January 2000

Accepted 7 April 2000
0.006: $\mathrm{n}=13) ; 3-0.143(0.136 \pm 0.004 ; \mathrm{n}=13) ; 4$ $-0.083(0.080 \pm 0.002 ; \mathrm{n}=13) ; 5-0.173(0.168 \pm$ $0.007 ; \mathrm{n}=11)$. Palpal formula 1.4.2.3.5. Fifth palpomere shorter than palpomeres $3 \mathrm{rd}+4$ th and same length as 2 nd +4 th. Newstead's spines present on palpomeres 2, 3, 4 and 5. Antennae with easily observed ascoids, absent from flagellomeres AXIV-AXVI. Proximal prolongation of ascoid short, not reaching the base of the flagellomere. Distal prolongation long, extending to next flagellomere. External ascoids situated more distally than internal ones on AIII-AVIII. Papillae present on segments AIII-AV and AXIII-AXVI. Length of flagellomere AIII $-0.270(0.280 \pm 0.006$; $\mathrm{n}=13)$; AIV $-0.173(0.176 \pm 0.005 ; \mathrm{n}=13) ; \mathrm{AV}-$ $0.173(0.175 \pm 0.004 ; \mathrm{n}=13)$. Ratio AXVI/AXV 0.73:1. Ratio AIII/LE 1.35:1.

Ventrocervical sensillae absent from cervix. Thorax: notum, pleurae and legs dark brown, pleurae somewhat paler than notum. Fore and hind femurs of equal length $1.125(1.072 \pm 0.035 ; \mathrm{n}=$ 13 ) and $1.125(1.068 \pm 0.037 ; \mathrm{n}=10)$, respectively. Middle femur shorter, length $1.042(0.996 \pm 0.044$; $\mathrm{n}=12$ ). Ratio basitarsus $1 /$ basitarsi $2+3+4+5$ of foreleg $1.00(0.98 ; \mathrm{n}=13)$; median leg $1.06(1.03$; $\mathrm{n}=12)$ and hindleg $1.15(1.10 ; \mathrm{n}=9)$. Wing broad, maximum width $0.878(0.814 \pm 0.043 ; \mathrm{n}=13)$. Length of principal wing sections: $\alpha(\mathrm{IR} 2)-0.686$ $(0.657 \pm 0.042 ; \mathrm{n}=13) ; \beta(\mathrm{R} 2+3)-0.315(0.310$ $\pm 0.023 ; \mathrm{n}=13) ; \gamma(\mathrm{R} 2+3+4)-0.315(0.318 \pm$ $0.019 ; \mathrm{n}=13$ ); $\delta$ (part of R1 extending beyond junction of R2 + R3) - $0.302(0.234 \pm 0.033 ; n=$ 13); R5 - 1.591 (1.511 $\pm 0.057 ; \mathrm{n}=13)$.

Katepisternum without anterior cerdae. Abdomen: coxite length $0.470(0.454 \pm 0.014 ; \mathrm{n}=$ 13 ), maximum width 0.167 with tuft of approximately $70(60-90 ; n=13)$ fine setae located from middle of structure to distal region. Style length 

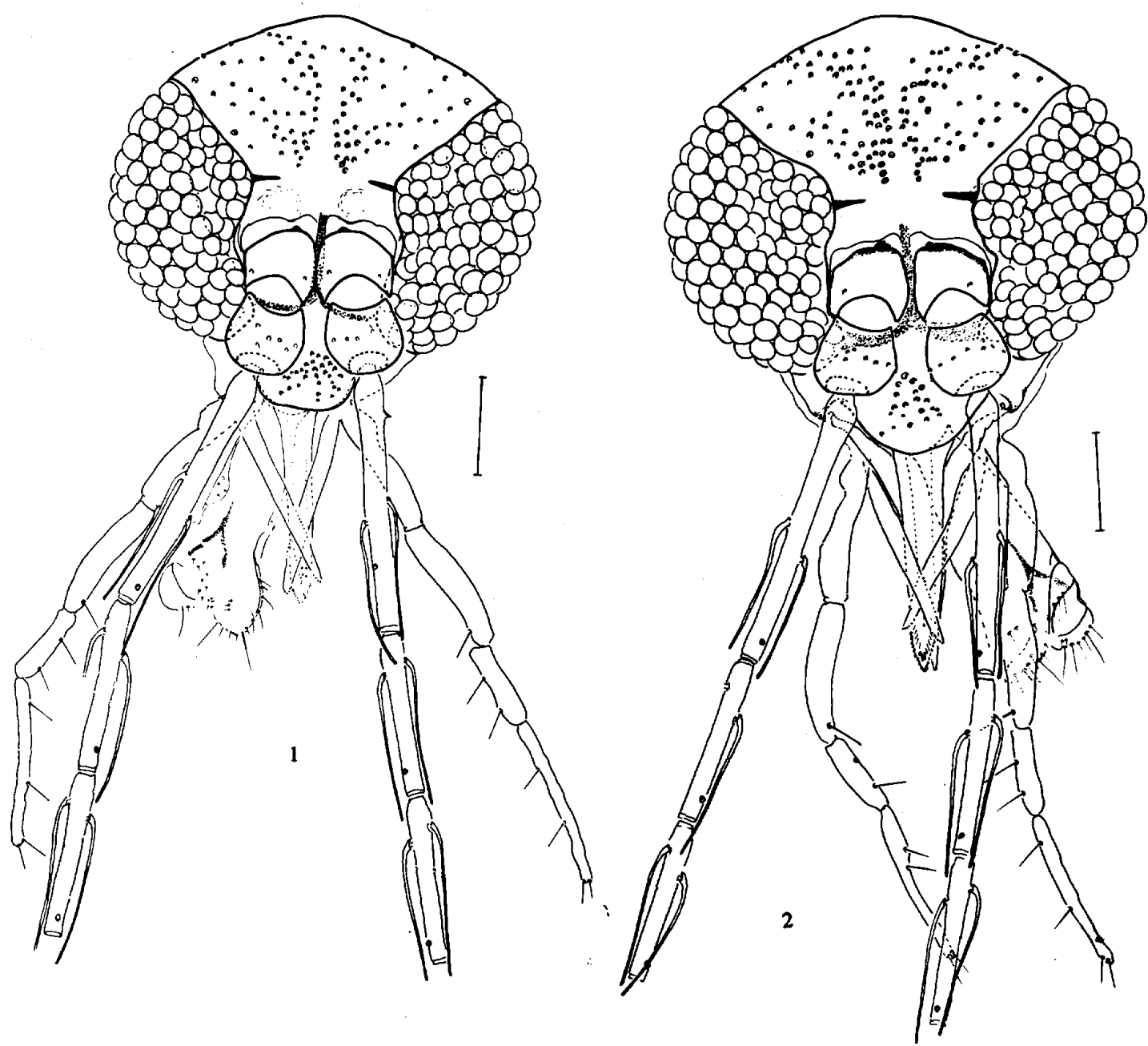

Lutzomyia naftalekatzi n. sp. - Fig. 1: head (female). Fig. 2: head (male). Bar: $100 \mu \mathrm{m}$

$0.266(0.251 \pm 0.015 ; \mathrm{n}=13)$. Style bearing four strong spines, one being apical, one intermediate and two inserted at same level on basal third of structure. Subterminal setae absent. Paramere simple, with distal group of setae in the middle of structure. Lateral lobe length $0.546(0.524 \pm 0.019$; $\mathrm{n}=13$ ), extends beyond coxite. Maximum width $0.040(0.042 \pm 0.003 ; \mathrm{n}=13)$. Aedeagus simple and pointed. Genital pump length $0.217(0.215 \pm$ $0.007 ; \mathrm{n}=13$ ). Genital filaments length 0.556 $(0.521 \pm 0.024)$ or 2.56 times length of genital pump. Tip of genital filaments twisted into an Sshape.

Allotype (female): smaller than male, total body length $3.371(3.693 \pm 0.084 ; \mathrm{n}=11)$. Coloration similar to that of male.

Head: length $0.310(0.299 \pm 0.012 ; \mathrm{n}=11)$, not including clypeus of length $0.127(0.125 \pm 0.004$; $\mathrm{n}=11$ ). Ratio head/clypeus 2.44 :1. Interocular dis- tance $0.140(0.148 \pm 0.005 ; \mathrm{n}=11)$. Labrum also relatively short, length $0.230(0.225 \pm 0.008 ; n=$ 11). Maxilla with a row of external longitudinal teeth. Lengths of palpomeres: $1-0.043(0.043 \pm$ $0.002 ; \mathrm{n}=11) ; 2-0.103(0.101 \pm 0.006: \mathrm{n}=11) ; 3$ $-0.143(0.144 \pm 0.007 ; \mathrm{n}=11) ; 4-0.083(0.085 \pm$ $0.004 ; \mathrm{n}=11) ; 5-0.163(0.165 \pm 0.004 ; \mathrm{n}=10)$. Palpal formula 1.4.2.3.5. Fifth palpomere shorter than palpomeres $3 \mathrm{rd}+4$ th and $2 \mathrm{nd}+4$ th. Newstead's spines present on palpomeres II, III, IV and V. Ascoids present on AIII-AXVI, proximal prolongation short and distal prolongation long, extending to next flagellomere. External ascoids situated more distally than internal ones on AIII-AVIII. Papillae present on segments AIIIAV and AXII-AXVI. Length of flagellomere AIII $-0.300(0.277 \pm 0.012 ; \mathrm{n}=11) ; \mathrm{AIV}-0.180(0.165$ $\pm 0.007 ; \mathrm{n}=11) ; \mathrm{AV}-0.173(0.164 \pm 0.005 ; \mathrm{n}=$ 11). Ratio AXVI/AXV 0.81:1. Cibarium with row 


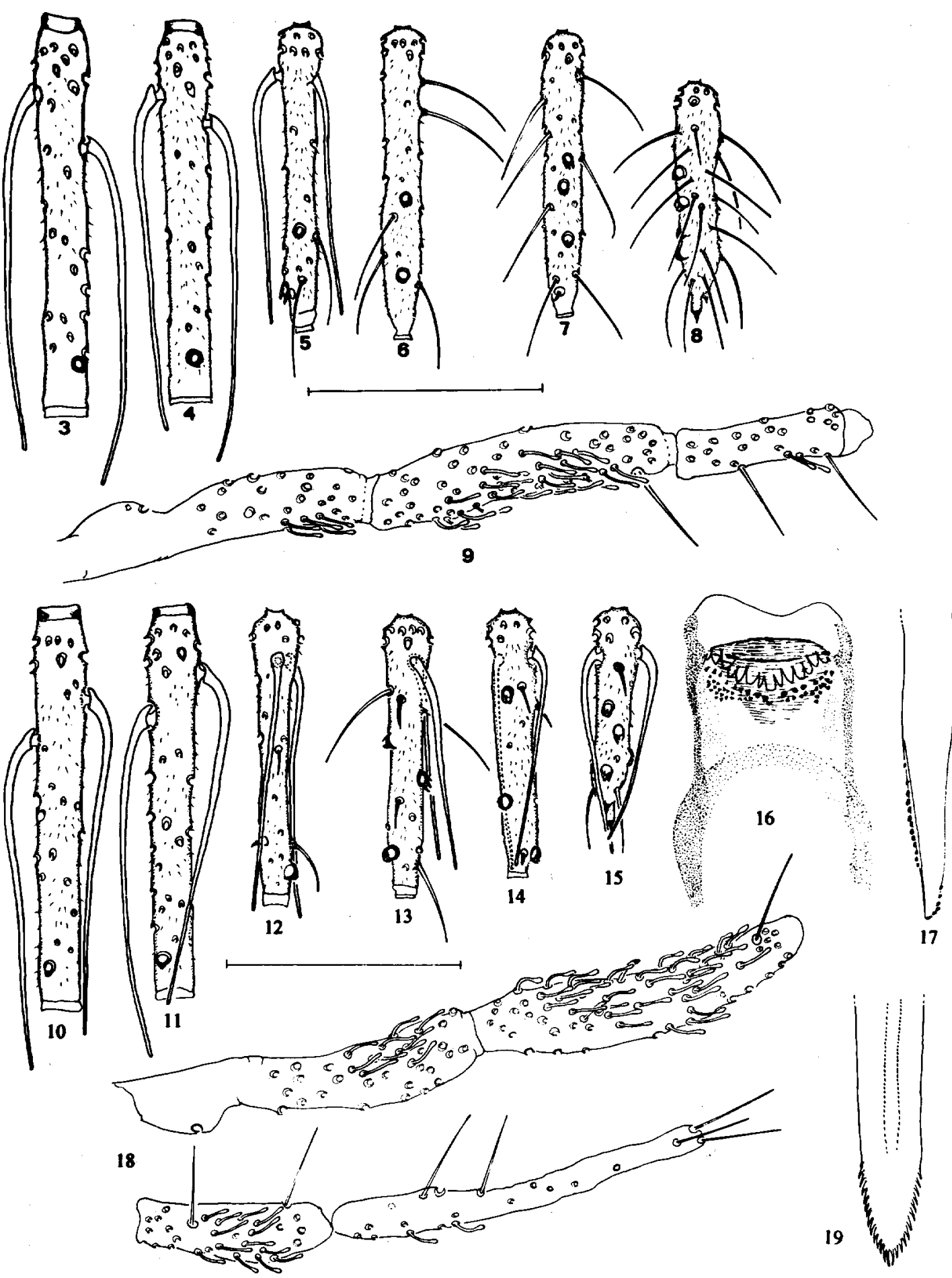

Lutzomyia naftalekatzi n. sp. Fig. 3: AIV (male). Fig. 4: AV (male). Fig. 5: AXIII (male). Fig. 6: AXIV (male). Fig. 7: AXV (male). Fig. 8: AXVI (male). Fig. 9: palpomeres 1-4 (male). Fig. 10: AIV (female). Fig. 11: AV (female). Fig. 12: AXIII (female). Fig. 13: AXIV (female). Fig. 14: AXV (female). Fig. 15: AVVI (female). Fig. 16: cibarium (female). Fig. 17: maxillae (female). Fig. 18: palpomeres 1-5 (female). Fig. 19: apical region of the hypopharynx (female). Bar: $100 \mu \mathrm{m}$ 

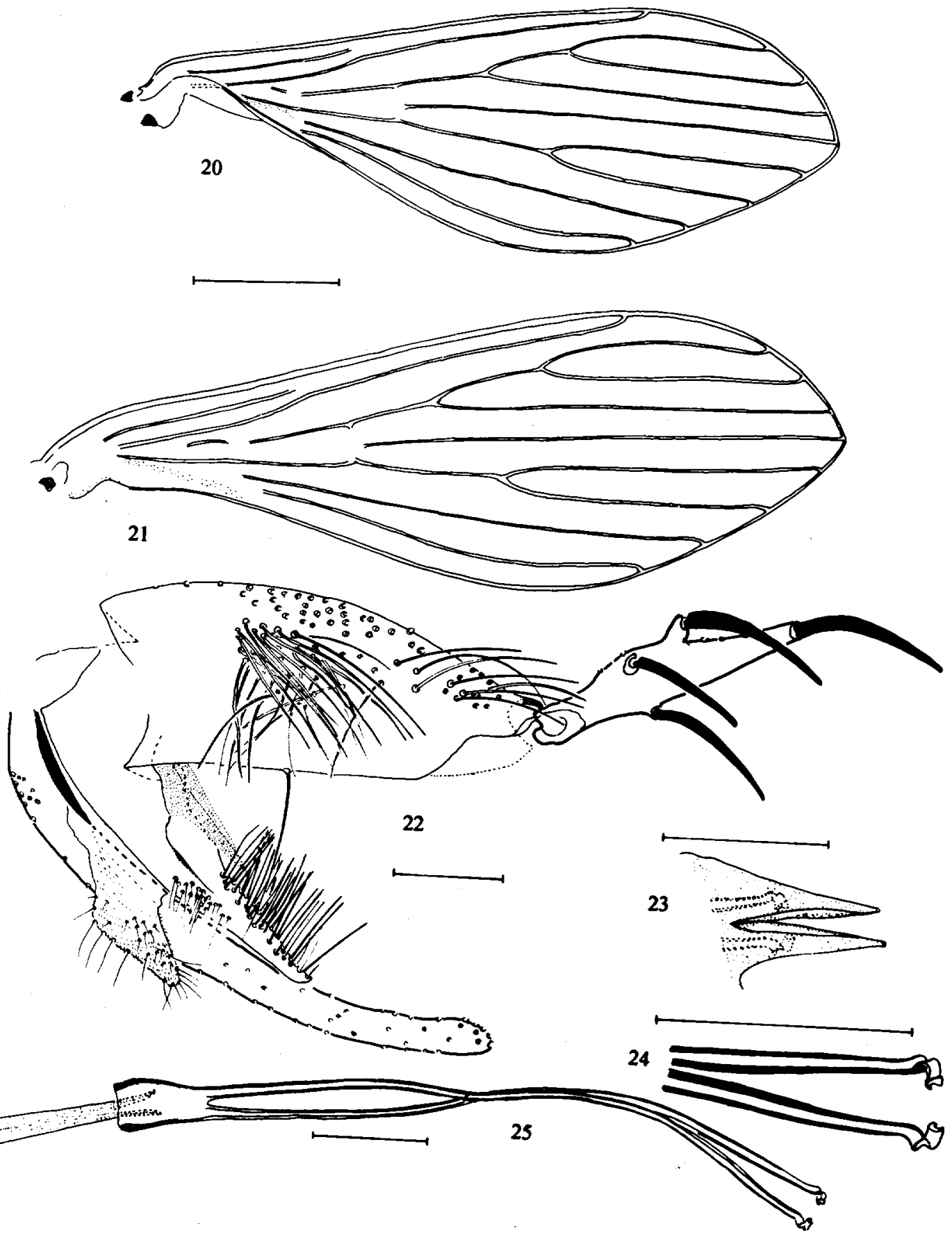

Lutzomyia naftalekatzi n. sp. - Fig. 20: wing (male). Fig. 21: wing (female). Bar: 500 um. Fig. 22: genitalia (male). Fig. 23: aedeagus (male). Fig. 24: tip of genital filament (male). Fig. 25: genital pump and filament (male). Bar: $100 \mu \mathrm{m}$

of 12 conspicuous horizontal teeth, wide at the base. Approximately 50 vertical teeth distributed among three transverse rows and 3-4 situated more laterally. Lateral teeth absent. Cibarial arch incomplete and pigment patch not well defined. Pharynx with apical striations.

Thorax: as in the male. Fore and hind femurs of equal length $1.138(1.128 \pm 0.030 ; \mathrm{n}=11)$ and $1.138(1.111 \pm 0.039 ; \mathrm{n}=10)$, respectively. Middle femur shorter, length $1.070(1.030 \pm 0.040 ; \mathrm{n}=$ 
10). Ratio basitarsus $1 /$ basitarsi $2+3+4+5$ of foreleg $1.00(0.97 ; \mathrm{n}=11)$; median leg $1.09(1.05 ; \mathrm{n}=$ $10)$ and hindleg $1.14(1.13 ; \mathrm{n}=10)$. Wing broad, maximum width $0.946(0.893 \pm 0.033 ; \mathrm{n}=11)$. Length of principal wing sections: $\alpha(\mathrm{IR} 2)-0.782$ $(0.769 \pm 0.031 ; \mathrm{n}=11) ; \beta(\mathrm{R} 2+3)-0.384(0.328$ $\pm 0.023 ; \mathrm{n}=11) ; \gamma(\mathrm{R} 2+3+4)-0.302(0.319 \pm$ $0.024 ; \mathrm{n}=11$ ); $\delta$ (part of R1 extending beyond junction of R2 + R3) $-0.329(0.326 \pm 0.020 ; \mathrm{n}=$ $11)$; $\mathrm{R} 5-1.659(1.633 \pm 0.035 ; \mathrm{n}=11)$.

Abdomen: cercus simple, length 0.207 (0.211 \pm $0.008 ; \mathrm{n}=11)$. Spermathecae globose, length 0.043 $(0.040 \pm 0.006 ; \mathrm{n}=11)$ width $0.028(0.047 \pm 0.003$; $\mathrm{n}=11)$. Head of spermatheca partially obscured and poorly defined. Entire length of individual ducts not visible in allotype or paratypes. Length of discernible region in 0.120 (allotype), 0.0630.170 (paratypes; $\mathrm{n}=11$ ). Common duct not visible in any of the type specimens.

Collection data and deposition of type material. Holotype male and allotype female collected by $\mathrm{C}$ Givaldo in a chicken coop at Refrigério, municipality of Amaraji, Pernambuco, Brazil, on 18 December 1995, together with 22 paratypes (12 males and 10 females). Material collected by direct aspiration and using CDC light traps. Holotype and allotype deposited in the phlebotomine sand fly collection at the Centro de Pesquisas René Rachou, Belo Horizonte, Minas Gerais, Brazil, together with 16 paratypes (nine males and seven females). One pair of paratypes (one male and one female) each donated to the collections of the Faculdade de Saúde Pública, Universidade de São Paulo, Brazil; Instituto Oswaldo Cruz, Rio de Janeiro, Brazil; and Natural History Museum, London, United Kingdom.

Type locality: the type locality $\left(8^{\circ} 29^{\prime} \mathrm{S}, 35^{\circ} 35^{\prime} \mathrm{W}\right)$ lies at an elevation of $310 \mathrm{~m}$ above sea level in southwest Pernambuco, a region of intensive agriculture, consisting predominantly of sugar cane plantations with some cultivation of bananas, cassava and indigenous fruit crops. Average yearround temperature is $24^{\circ} \mathrm{C}$ and relative humidity is $80 \%$.

\section{REMARKS}

The morphological characteristics of $L$. naftalekatzi $\mathrm{n}$. sp. permit us to include this species in the L. aragaoi species group, series aragaoi (Theodor 1965). The twisted tip of the genital filaments resemble those of $L$. carpenteri (Fairchild \& Hertig), L. coutinhoi (Mangabeira), L. aragaoi (Costa Lima) and L. antezanai Le Pont, Dujardin, Mouchet \& Desjeux, but differs by aspect of the coxite that have one tuft with $60-90$ of persistent setae and by the shape of the paramere that is simple and have dorsal setae in the apical third of structure.

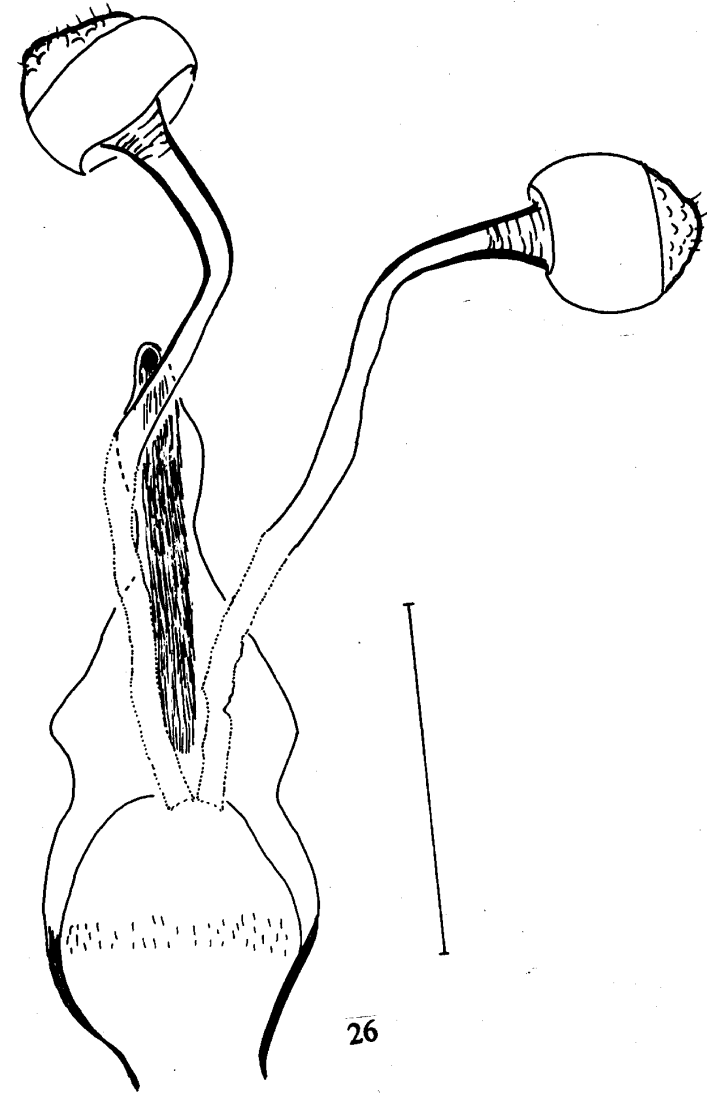

Lutzomyia naftalekatzi $\mathrm{n}$. sp - Fig. 26: spermathecae (female). Bar: $100 \mu \mathrm{m}$

The spermathecae of the new species resemble those of L. barrettoi majuscula Young, L. texana (Dampf) and L. aragaoi. It differs from these by the smaller size of the spermathecae.

$L$. naftalekatzi is clearly larger than all other members of the L. aragaoi species group. Females of the new species can be distinguished from others in the group by the fact that all the antennal flagellomeres bear ascoids. The sexes could be associated based on genital and non-sexual characteristics including size, pattern of thoracic pigmentation and the absence of other species in the collection that could not be identified with certainty.

\section{ACKNOWLEDGEMENTS}

To Dr Bruce Alexander, Centro de Pesquisas René Rachou-Fiocruz, Belo Horizonte, Minas Gerais, for his critical review of the manuscript and Dr Eunice A Bianchi Galati, Faculdade de Saúde Pública da Universidade de São Paulo, for the drawings of the new species. 


\section{REFERENCES}

Brandão-Filho SP, Carvalho FG, Felinto de Brito ME, Almeida FA, Nascimento LA 1994. American cutaneous leishmaniasis in Pernambuco, Brazil: ecoepidemiological aspects in 'Zona da Mata' region. Mem Inst Oswaldo Cruz, 89: 445-449.

CIPA Group. Bermudes H, Dedet JP, Falcão AL, Feliciangeli D, Ferro C, Galati EAB, Gomes EL, Herrero MV, Hervas D, Lebbe J, Morales A, Oguzuku E, Perez E, Rangel EF, Sherlock IA, Torres
M, Vignes R, Wolff M 1991. Proposition of a standard description for phlebotomine sand flies. Parassitologia 33 (Suppl.): 127-135.

Felinto de Brito ME, Brandão-Filho SP, Salles NR, Cupolito E, Grimaldi Jr G, Momen H 1993. Human cutaneous leishmaniasis due to a new enzymatic variant of Leishmania (Viannia) braziliensis ocurring in Pernambuco, Brazil. Mem Inst Oswaldo Cruz 88: 633-634.

Theodor, O 1965. On the classification of American Phlebotominae. J Med Ent 2: 171-197. 